NBER WORKING PAPER SERIES

INTERTEMPORAL DISTURBANCES

\author{
Giorgio E. Primiceri \\ Ernst Schaumburg \\ Andrea Tambalotti \\ Working Paper 12243 \\ http://www.nber.org/papers/w12243
}

\author{
NATIONAL BUREAU OF ECONOMIC RESEARCH \\ 1050 Massachusetts Avenue \\ Cambridge, MA 02138 \\ May 2006
}

We thank Larry Christiano and Mark Gertler for many useful conversations, our discussants Marc Giannoni, Massimiliano Pisani, Ricardo Reis and Andrea Raffo for their insightful comments, and seminar participants at the Federal Reserve Banks of Chicago and New York, Northwestern University, Humboldt University Berlin, the 2005 SED Annual Meeting, the Cleveland Fed conference on Empirical Methods and Applications for DSGE and Factor Models, the New York Area Workshop on Monetary Policy, the IV Workshop on Dynamic Macroeconomics and the Macroeconomic System Meeting. We are especially grateful to Alejandro Justiniano for many discussions on this and related projects and for sharing his codes for the estimation of DSGE models. The views expressed in this paper are those of the authors and do not necessarily reflect the position of the Federal Reserve Bank of New York or the Federal Reserve System. The views expressed herein are those of the author(s) and do not necessarily reflect the views of the National Bureau of Economic Research.

(C2006 by Giorgio E. Primiceri, Ernst Schaumburg and Andrea Tambalotti. All rights reserved. Short sections of text, not to exceed two paragraphs, may be quoted without explicit permission provided that full credit, including (C) notice, is given to the source. 
Intertemporal Disturbances

Giorgio E. Primiceri, Ernst Schaumburg, and Andrea Tambalotti

NBER Working Paper No. 12243

May 2006

JEL No. E30, E32, E44

\section{$\underline{\text { ABSTRACT }}$}

Disturbances affecting agents intertemporal substitution are the key driving force of macroeconomic fluctuations. We reach this conclusion exploiting the bond pricing implications of an estimated general equilibrium model of the U.S. business cycle with a rich set of real and nominal frictions.

Giorgio E. Primiceri

Department of Economics

Northwestern University

2001 Sheridan Road

Evanston, IL 60208

and NBER

g-primiceri@northwestern.edu

Ernst Schaumburg

Kellogg School of Management

Northwestern University

2001 Sheridan Road

Evanston, IL 60208

e-schaumburg@northwestern.edu

Andrea Tambalotti

Macroeconomic and Monetary Studies Function

Federal Reserve Bank of New York

33 Liberty Street

New York, NY 10045

andrea.tambalotti@ny.frb.org 


\title{
INTERTEMPORAL DISTURBANCES
}

\author{
GIORGIO E. PRIMICERI, ERNST SCHAUMBURG, AND ANDREA TAMBALOTTI
}

\begin{abstract}
Disturbances affecting agents' intertemporal substitution are the key driving force of macroeconomic fluctuations. We reach this conclusion exploiting the bond pricing implications of an estimated general equilibrium model of the U.S. business cycle with a rich set of real and nominal frictions.
\end{abstract}

\section{InTRODUCTION}

Macroeconomic models imply two broad classes of optimization conditions. On the one hand, intratemporal first order conditions equate the marginal rate of substitution (MRS) between two goods consumed at the same time to their relative price and, through this, to the marginal rate of transformation (MRT). On the other hand, intertemporal first order conditions equate the MRS of the same good across time to the relative price and to the MRT.

In a stochastic general equilibrium, macroeconomic fluctuations originate from shocks hitting these equilibrium conditions. We refer to the shocks

Date: First draft: October 2005. This version: April 2006.

We thank Larry Christiano and Mark Gertler for many useful conversations, our discussants Marc Giannoni, Massimiliano Pisani, Ricardo Reis and Andrea Raffo for their insightful comments, and seminar participants at the Federal Reserve Banks of Chicago and New York, Northwestern University, Humboldt University Berlin, the 2005 SED Annual Meeting, the Cleveland Fed conference on "Empirical Methods and Applications for DSGE and Factor Models," the "New York Area Workshop on Monetary Policy," the "IV Workshop on Dynamic Macroeconomics" and the "Macroeconomic System Meeting." We are especially grateful to Alejandro Justiniano for many discussions on this and related projects and for sharing his codes for the estimation of DSGE models. The views expressed in this paper are those of the authors and do not necessarily reflect the position of the Federal Reserve Bank of New York or the Federal Reserve System. 
that directly perturb the intratemporal first order conditions as intratemporal disturbances. This distinguishes them from intertemporal disturbances, which perturb instead the agents' intertemporal first order conditions. ${ }^{1}$

This distinction is useful to state clearly the main result of this paper: intertemporal disturbances are the key source of macroeconomic fluctuations.

This finding is quite surprising, at least if considered through the lens of some prominent work in macroeconomics. The Real Business Cycle literature, for example, has been extremely succesful in demonstrating that economic fluctuations can be largely accounted for by neutral shifts in the production function (Prescott (1986), King and Rebelo (1999)). ${ }^{2}$ Similarly, Hall (1997) found that most of the movements in employment over the business cycle are due to intratemporal "preference" shocks. These results have been confirmed and extended by Mulligan (2002b), Mulligan (2002c) and Chari, Kehoe, and McGrattan (2005). Chari, Kehoe, and McGrattan (2005) in particular find that intertemporal shocks - investment wedges in their accounting taxonomy - are a negligible source of business cycle fluctuations. This is true in an unconditional sense, for the entire postwar period, as well as more specifically when accounting for the Great Depression and the 1982 recession.

What is the source of the discrepancy between our results and those in this literature? We argue that the conclusion that intertemporal disturbances are unimportant stems from the common practice of disregarding asset market data in macroeconomics. In fact, the studies mentioned above share one important characteristic: they concentrate on economies in which capital is the only asset. As a consequence, their equilibrium conditions include only one intertemporal Euler equation, that for the optimal choice of capital. With only one Euler equation, only one intertemporal "residual" (or wedge)

\footnotetext{
1 This distinction is not necessarily a partition. Some shocks can perturb both the intratemporal and the intertemporal first order conditions.

${ }^{2}$ We classify neutral technology shocks as intratemporal disturbances, because they directly perturb the contemporaneous relation between inputs and output. However, this choice of label is inconsequential for the substantive results of the paper regarding the sources of business cycle fluctuations.
} 
is identified in this economy. The results in the literature suggest that this wedge is small.

In contrast to this literature, we consider an economy in which a shortterm nominal bond is traded along with physical capital. In this economy, the equilibrium conditions include two Euler equations, derived from the optimal choice of each of the two assets. The key point is that with two Euler equations we can identify two separate intertemporal disturbances, as long as we include the short-term interest rate among the observables. We model the first disturbance as a shock to the stochastic discount factor, which captures exogenous fluctuations in preferences, as well as unmodelled distortions in consumption choices. The second disturbance is a shock to the rate of return on capital, which might be caused for example by changes in the efficiency of the investment technology.

We find that both disturbances contribute substantially to fluctuations, even if the contribution of the combined wedge is negligible in models with only one intertemporal Euler equation. Intuitively, large exogenous variations in the stochastic discount factor are necessary to repair the very poor bond pricing performance of the standard Euler equation. Unfortunately though, the resulting discount factor does not price the capital stock correctly. Hence the need for large fluctuations in the disturbance to the rate of return.

This is not the first work in macroeconomics to emphasize the importance of intertemporal shocks as sources of business cycles. Fisher (2005) identifies a sizable contribution to fluctuations of an investment specific technology shock, one of the intertemporal shocks we include in our model, in the context of a structural VAR. Greenwood, Hercowitz, and Krusell (2000) show that such a shock could explain about a third of output fluctuations in a calibrated real business cycle model, while Greenwood, Hercowitz, and Krusell (1997) emphasize its role as a contributor to long-run growth. All these studies use direct observations on the relative price of investment as a proxy for the investment specific technological shock. On the contrary, we measure the contribution of intertemporal disturbances to fluctuations 
indirectly, as the shocks needed to reconcile the Euler equations for bonds and capital with data on quantities and interest rates. In this respect, the paper closest to ours is Justiniano and Primiceri (2005), who work with a very similar model, but focus on explaining the decline in volatility of U.S. GDP.

Our findings are consistent with a long line of research in finance, dating back at least to Hansen and Singleton's (1982 and 1983) seminal studies on the estimation of consumption Euler equations. ${ }^{3}$ This literature had varying degrees of success in recovering "reasonable" estimates of taste parameters. For example, Eichenbaum, Hansen, and Singleton (1988) and Mankiw, Rotemberg, and Summers (1985) reach opposite conclusions about the implications of their parameter estimates for the plausibility of the implied utility function. However, one result is remarkably robust across all these studies. The overidentifying restrictions embedded in the Euler equation are consistently and overwhelmingly rejected. In other words, the Euler equation errors are statistically large.

Our work is in line with this result, but extends it in one important direction. As in the finance literature, we document the size of the statistical errors in the model's Euler equations. In addition, by embedding these first order conditions into a general equilibrium framework, we can measure the economic importance of the disturbances in terms of their contribution to fluctuations. We find that intertemporal disturbances account for a large portion of the variation in U.S. output, consumption, investment and hours.

One possible reaction to this finding is simply to de-emphasize the pricing implications of macro models, and focus instead on their success with quantities. This approach is well established in macroeconomics, and has proved fruitful in addressing many interesting questions. However, we find it unsatisfactory, for at least two reasons. First, in a decentralized equilibrium,

\footnotetext{
${ }^{3}$ See Singleton (1990) for a survey of the early literature and Hall (1988) for a more macroeconomic approach to the same issue. Campbell (2003) provides a more recent rendition of the same results, as well as an extension to several countries.
} 
prices are the signals that lead agents to align marginal rates of substitution and transformation. Models that achieve the correct alignment of those rates, but with the wrong prices, should at least be "puzzling." Trying to solve this puzzle is a challenge squarely within the realm of macroeconomics, as forcefully argued by Cochrane (2005). ${ }^{4}$ Second, disregarding asset prices is not a viable approach, if we are interested in modeling the short-term nominal interest rate as the main instrument of monetary policy, as in the modern New Keynesian literature (Woodford (2003), Smets and Wouters (2003a), Christiano, Eichenbaum, and Evans (2005))

The paper is organized as follows. Section 2 presents the intuition behind our results, in the context of a stylized model. Section 3 introduces a more realistic model of the U.S. business cycle, with a rich set of nominal and real frictions. Section 4 and 5 present the estimation results for the baseline model and for several restricted versions of this model. Section 6 concludes.

\section{The Importance of Intertemporal Disturbances}

This section presents a stylized general equilibrium model, which is helpful in illustrating the intuition behind our main results.

Consider the problem of a representative household maximizing the familiar utility function, which depends on consumption $(C)$ and hours worked $(L)$ :

$$
E_{t} \sum_{s=0}^{\infty} \beta^{s} b_{t+s}\left[\frac{C_{t+s}^{1-\theta}}{1-\theta}-\frac{L_{t+s}^{1+\nu}}{1+\nu}\right] .
$$

In this formulation, $b_{t}$ is an exogenous shock to the consumer's impatience, which affects both the marginal utility of consumption and the marginal disutility of labor. The household owns the firms and the capital stock. Therefore, its budget constraint is given by

$$
C_{t}+T_{t}+I_{t}+B_{t} \leq\left(1+r_{t-1}\right) B_{t-1}+\Pi_{t}+w_{t} L_{t}+r_{t}^{k} K_{t}
$$

where $T_{t}$ represents lump-sum tax payments, $I_{t}$ is investment, $B_{t}$ is the household's holdings of government bonds, $r_{t}$ is the risk-free real interest

${ }^{4}$ A possible solution to the "puzzle" lies in the observation that prices might not be allocative. This is plausible in the case of wages, much less so in reference to asset prices. 
rate, $\Pi_{t}$ is the profit earned from owning the firms and $w_{t}$ is the real wage. Capital, denoted by $K_{t}$, is rented to firms at the rate $r_{t}^{k}$. Households accumulate the capital stock according to the equation

$$
K_{t+1}=(1-\delta) K_{t}+\mu_{t} I_{t}
$$

where $\delta$ denotes the capital depreciation rate. $\mu_{t}$ is an investment specific technology shock, a random disturbance to the efficiency with which consumption goods are transformed into capital, as in Greenwood, Hercowitz, and Krusell (1997) or Fisher (2005). Therefore, in a competitive equilibrium, $\mu_{t}^{-1}$ is equal to the relative price of investment.

In this economy, firms operate a Cobb-Douglas production function in capital and hours. They maximize profits, taking prices as given. We close the model with a Government, which finances its budget deficit by issuing the short term bonds held by households.

Focusing on the intertemporal first order conditions of the consumer problem, we have

$$
\begin{aligned}
1 & =E_{t}\left[M_{t+1}\left(1+r_{t}\right)\right] \\
1 & =E_{t}\left[M_{t+1} \mu_{t}\left(r_{t+1}^{k}+\frac{1-\delta}{\mu_{t+1}}\right)\right],
\end{aligned}
$$

with

$$
M_{t+1} \equiv \beta\left(\frac{C_{t+1}}{C_{t}}\right)^{-\theta} \frac{b_{t+1}}{b_{t}} .
$$

Equations (2.1) and (2.2) can be interpreted as pricing equations for the risk-free bond and the capital stock respectively. $M_{t+1}$ is the model's stochastic discount factor, which fluctuates endogenously with consumption, and exogenously with the taste disturbance $b_{t}$. The investment specific shock $\mu_{t}$, on the other hand, acts as a disturbance to the rate of return on capital. Both disturbances perturb the model's Euler equations. Therefore, we classify them as intertemporal disturbances. Our surprising finding is that these two shocks together are responsible for a large fraction of macroeconomic fluctuations in the Unites States.

Why are our results on the importance of these intertemporal disturbances so different from those in most of the macroeconomic literature? Because 
most of that literature ignores equation (2.1) and its empirical implications. For example, in Chari, Kehoe, and McGrattan's (2005) prototype economy, capital is the only asset. Therefore, equation (2.1) is redundant in the characterization of the equilibrium allocation. Moreover, markets are competitive, so that the rental rate in equation (2.2) can be substituted with the marginal product of capital. These restrictions have two important consequences. First, with only one Euler equation, it is possible to identify only one intertemporal wedge, a combination of the intertemporal disturbances $b_{t}$ and $\mu_{t}$. Second, this wedge is likely to be small, since equation (2.2) has the best chance of fitting the data when the rental rate is measured by the marginal product of capital (Mulligan (2002a) and Mulligan (2004)).

Why does the explicit consideration of equation (2.1) make such a dramatic difference? Because this equation fits the data very poorly when the rate of return is measured on asset markets, either as a stock return or as an interest rate on bonds (Hansen and Singleton (1982), Hansen and Singleton (1983), Hall (1988) and Campbell (2003)). This lack of fit means that the discrepancy between the discounted rate of return and one is statistically large. Therefore, a large taste shock $b_{t}$ is necessary to reconcile the observed market returns with the growth rate of consumption. This is true even under much more general specifications for $M_{t+1}$ than the one adopted here (Eichenbaum, Hansen, and Singleton (1988)). In fact, equation (2.1) is resoundingly rejected by tests of overidentifying restrictions, no matter what the utility specification, the measure of returns, the list of instruments, or the frequency of the observations (see Singleton (1990) for a survey.)

Figure 1 illustrates this argument quite effectively. It compares the growth rate of consumption with measures of the marginal product of capital and of the short-term real interest rate. Although consumption growth is more volatile than the marginal product of capital at high frequency, the two series clearly comove over the business cycle. The real interest rate, on the other hand, is significantly more volatile than consumption growth, especially in the second half of the sample, and there is hardly any comovement. Given 
this picture, significant differences in fit between equations (2.1) and (2.2) should not be surprising.

In summary, looking at Euler equations (2.1) and (2.2) jointly, rather than at (2.2) alone, leads to very different conclusions about the statistical size and the economic importance of intertemporal disturbances. The model's discount factor can price short-term bonds correctly only thanks to exogenous movements in $b_{t}$. But then, this same discount factor is unlikely to also price the capital stock, which was instead priced reasonably well by consumption growth alone. Hence the importance of the other intertemporal shock, $\mu_{t}$, to realign the return on capital with the discount factor needed to fit equation (2.1).

But is it important to distinguish the contributions of the two intertemporal disturbances to fluctuations? We think the answer is yes, at least in a world with frictions. In an efficient economy, $\mu_{t}$ and $b_{t}$ do not play economically independent roles. They both induce substitution of current consumption with investment, and therefore future consumption - $\mu_{t}$ by making investment cheaper, $b_{t}$ by making consumers more patient. Therefore, in such an economy, a unique intertemporal wedge effectively summarizes their effect. Not so in an economy with frictions, in which different shocks will in general propagate through different mechanisms. Therefore, if we wish to identify the sources of business cycles we need to model explicitly the frictions that propagate them.

Of course, modeling frictions explicitly has also some drawbacks, in particular because the identification of the shocks relies crucially on the exact specification of those frictions. This is why Bayesian estimation is particularly suitable in this context, since it allows an explicit formal comparison of the fit of models with alternative sets of frictions.

The aim of this section was to provide some intuition for our findings on the role of intertemporal shocks in economic fluctuations. The rest of the paper supplies the quantitative underpinnings of the arguments developed 
here, in the context of an estimated DSGE model with a rich set of frictions. We present this baseline model in section 3 and 4 . Then, in section 5 , we study the effect of various restrictions on the model's variance decomposition. In particular, we show that in the baseline model intertemporal shocks explain the bulk of macroeconomic fluctuations, only if we include the short-term interest rate among the observables and equation (2.1) among the constraints. Moreover, this result depends crucially on the inclusion of the nominal and real frictions that our estimation procedure suggests are important in fitting the data. In fact, the role of intertemporal shocks is negligible in a version of the model restricted to resemble a prototypical stochastic growth model. On the other hand, intertemporal shocks become paramount again in a small monetary model with no investment, in which output is equal to consumption and thus equation (2.1) is the only Euler equation.

\section{A model of the US Business CyCle}

This section outlines our baseline model of the U.S. business cycle. This is a medium-scale DSGE model, with a host of nominal and real frictions, along the lines of Christiano, Eichenbaum, and Evans (2005). An important feature of this model is that its fit to U.S. data has been shown to be competitive with that of Bayesian vector autoregressions (Smets and Wouters (2003b) and Del Negro, Schorfheide, Smets, and Wouters (2004)). As Smets and Wouters (2003a) and Del Negro, Schorfheide, Smets, and Wouters (2004), we estimate this model with Bayesian methods, and use it to document the quantitative importance of the qualitative insights discussed in section 2 . Moreover, in section 5 we consider several carefully restricted versions of the baseline model, to highlight the source of the differences between our results and those in the literature.

The model is populated by five classes of agents. Producers of final goods, which "assemble" a continuum of intermediate goods produced by monopolistic intermediate goods producers. Households, who consume the final 
good, accumulate capital, and supply differentiated labor services to competitive "employment agencies". A Government. We present their optimization problems in turn.

3.1. Final goods producers. At every point in time $t$, perfectly competitive firms produce the final consumption good $Y_{t}$, combining a continuum of intermediate goods $Y_{t}(i), i \in[0,1]$ according to the technology

$$
Y_{t}=\left[\int_{0}^{1} Y_{t}(i)^{\frac{1}{1+\lambda_{p, t}}} d i\right]^{1+\lambda_{p, t}}
$$

$\lambda_{p, t}$ follows the exogenous stochastic process

$$
\log \lambda_{p, t}=\left(1-\rho_{p}\right) \log \lambda_{p}+\rho_{p} \log \lambda_{p, t-1}+\varepsilon_{p, t},
$$

where $\varepsilon_{p, t}$ is $i . i . d . N\left(0, \sigma_{p}^{2}\right)$. Profit maximization and the zero profit condition imply the following relationship between the price of the final good, $P_{t}$, and the prices of the intermediate goods, $P_{t}(i)$

$$
P_{t}=\left[\int_{0}^{1} P_{t}(i)^{\frac{1}{\lambda_{p, t}}} d i\right]^{\lambda_{p, t}},
$$

and the demand function for the intermediate good $i$

$$
Y_{t}(i)=\left(\frac{P_{t}(i)}{P_{t}}\right)^{-\frac{1+\lambda_{p, t}}{\lambda_{p, t}}} Y_{t} .
$$

3.2. Intermediate goods producers. A monopolist produces the intermediate good $i$ according to the production function

$$
Y_{t}(i)=\max \left\{A_{t}^{1-\alpha} K_{t}(i)^{\alpha} L_{t}(i)^{1-\alpha}-A_{t} F ; 0\right\}
$$

where $K_{t}(i)$ and $L_{t}(i)$ denote the capital and labor inputs for the production of good $i$ and $F$ represents a fixed cost of production. $A_{t}$ is an exogenous stochastic process capturing the effects of technology, whose growth rate $\left(z_{t} \equiv \Delta \log A_{t}\right)$ evolves according to

$$
z_{t}=\left(1-\rho_{z}\right) \gamma+\rho_{p} z_{t-1}+\varepsilon_{z, t}
$$

where $\varepsilon_{z, t}$ is $i . i . d . N\left(0, \sigma_{z}^{2}\right)$. Therefore, the level of technology is non stationary. 
As in Calvo (1983), a fraction $\xi_{p}$ of firms cannot re-optimize their prices and, therefore, set their prices following the indexation rule

$$
P_{t}(i)=P_{t-1}(i) \pi_{t-1}^{\iota_{p}} \pi^{1-\iota_{p}}
$$

where $\pi_{t} \equiv \frac{P_{t}}{P_{t-1}}$ and $\pi$ denotes the steady state value of $\pi_{t}$. On the other hand, re-optimizing firms choose their price, $\tilde{P}_{t}(i)$, by maximizing the present value of future profits, subject to the usual cost minimization condition,

$E_{t} \sum_{s=0}^{\infty} \xi_{p}^{s} \beta^{s} \lambda_{t+s}\left\{\left[\tilde{P}_{t}(i)\left(\Pi_{j=0}^{s} \pi_{t-1+j}^{\iota_{p}} \pi^{1-\iota_{p}}\right)\right] Y_{t+s}(i)-\left[W_{t} L_{t}(i)+r_{t}^{k} K_{t}(i)\right]\right\}$

where $\lambda_{t+s}$ is the marginal utility of consumption, and $W_{t}$ and $r_{t}^{k}$ denote the nominal wage and the rental rate of capital.

3.3. Employment Agencies. Firms are owned by a continuum of households, indexed by $j \in[0,1]$. As in Erceg, Henderson, and Levin (2000), each household is a monopolistic supplier of specialized labor, $L_{t}(j)$. A large number of "employment agencies" combines this specialized labor into labor services available to the intermediate firms, according to

$$
L_{t}=\left[\int_{0}^{1} L_{t}(j)^{\frac{1}{1+\lambda w}} d j\right]^{1+\lambda_{w}}
$$

Profit maximization and the zero profit condition for the perfectly competitive employment agencies imply the following relationship between the wage paid by the intermediate firms and the wage received by the supplier of labor of type $j, W_{t}(j)$

$$
W_{t}=\left[\int_{0}^{1} W_{t}(j)^{\frac{1}{\lambda w}} d j\right]^{\lambda_{w}}
$$

and the labor demand function

$$
L_{t}(j)=\left(\frac{W_{t}(j)}{W_{t}}\right)^{-\frac{1+\lambda_{w}}{\lambda_{w}}} L_{t}
$$


3.4. Households. Each household maximizes the utility function

$$
E_{t} \sum_{s=0}^{\infty} \beta^{s} b_{t+s}\left[\log \left(C_{t+s}-h C_{t+s-1}\right)-\varphi_{t+s} \frac{L_{t+s}(j)^{1+\nu}}{1+\nu}\right],
$$

where $C_{t}$ is consumption and $h$ is the "degree" of habit formation. ${ }^{5} \varphi_{t}$ is a preference shock that affects the marginal disutility of labor, while $b_{t}$ is a "discount factor" shock affecting both the marginal utility of consumption and the marginal disutility of labor. These two shocks follow the stochastic processes

$$
\begin{aligned}
\log b_{t} & =\rho_{b} \log b_{t-1}+\varepsilon_{b, t} \\
\log \varphi_{t} & =\left(1-\rho_{\varphi}\right) \log \varphi+\rho_{\varphi} \log \varphi_{t-1}+\varepsilon_{\varphi, t}
\end{aligned}
$$

Note that we work with log utility to ensure the existence of a balanced growth path, as in the real business cycle tradition. Moreover, consumption is not indexed by $j$ because the existence of state contingent securities ensures that in equilibrium consumption and asset holdings are the same for all households.

The household's budget constraint is

$P_{t} C_{t}+P_{t} I_{t}+B_{t} \leq R_{t-1} B_{t-1}+Q_{t-1}(j)+\Pi_{t}+W_{t}(j) L_{t}(j)+r_{t}^{k} u_{t} \bar{K}_{t-1}-P_{t} a\left(u_{t}\right) \bar{K}_{t-1}$,

where $I_{t}$ is investment, $B_{t}$ is holdings of government bonds, $R_{t}$ is the gross nominal interest rate, $Q_{t}(j)$ is the net cash flow from participating in state contingent securities, and $\Pi_{t}$ is the per-capita profit accruing to households from ownership of the firms.

Households own capital and choose the capital utilization rate, $u_{t}$, which transforms physical capital into effective capital according to

$$
K_{t}=u_{t} \bar{K}_{t-1}
$$

Effective capital is then rented to firms at the rate $r_{t}^{k}$. The cost of capital utilization is $a\left(u_{t}\right)$ per unit of physical capital. As in Altig, Christiano,

\footnotetext{
${ }^{5}$ We assume a cashless limit economy as described in Woodford (2003).
} 
Eichenbaum, and Linde (2005), we assume that $u_{t}=1$ and $a\left(u_{t}\right)=0$ in steady state. The physical capital accumulation equation is

$$
\bar{K}_{t}=(1-\delta) \bar{K}_{t-1}+\mu_{t}\left(1-S\left(\frac{I_{t}}{I_{t-1}}\right)\right) I_{t},
$$

where $\delta$ denotes the depreciation rate. The function $S$ captures the presence of adjustment costs in investment, as in Christiano, Eichenbaum, and Evans (2005) and Altig, Christiano, Eichenbaum, and Linde (2005). We assume that $S^{\prime}=0$ and $S^{\prime \prime}>0$ in steady state. ${ }^{6} \mu_{t}$ is an investment specific technological shock affecting the efficiency with which consumption goods are transformed into capital. In equilibrium, $\mu_{t}$ can be interpreted as the inverse of the relative price of investment. We assume that it follows the exogenous process

$$
\log \mu_{t}=\rho_{\mu} \log \mu_{t-1}+\varepsilon_{\mu, t},
$$

where $\varepsilon_{\mu, t}$ is $i . i . d . N\left(0, \sigma_{\mu}^{2}\right)$.

As in Erceg, Henderson, and Levin (2000), a fraction $\xi_{w}$ of households cannot re-optimize their wages and, therefore, set them according to the indexation rule

$$
W_{t}(j)=W_{t-1}(j)\left(\pi_{t-1} e^{z_{t-1}}\right)^{\iota_{w}}\left(\pi e^{\gamma}\right)^{1-\iota_{w}}
$$

The remaining fraction of re-optimizing households maximizes instead

$$
E_{t} \sum_{s=0}^{\infty} \xi_{w}^{s} \beta^{s} b_{t+s}\left\{-\varphi_{t+s} \frac{L_{t+s}(j)^{1+\nu}}{1+\nu}\right\},
$$

subject to the labor demand function.

3.5. Government. Monetary policy sets short term nominal interest rates following a Taylor type rule of the form

$$
\frac{R_{t}}{R}=\left(\frac{R_{t-1}}{R}\right)^{\rho_{R}}\left[\left(\frac{\pi_{t}}{\pi}\right)^{\phi_{\pi}}\left(\frac{Y_{t} / A_{t}}{Y / A}\right)^{\phi_{Y}}\right]^{1-\rho_{R}} e^{\varepsilon_{M P, t}},
$$

where $R$ is the steady state for the nominal interest rate and $\varepsilon_{M P, t}$ is an i.i.d.N $\left(0, \sigma_{R}^{2}\right)$ monetary policy shock.

\footnotetext{
${ }^{6}$ Lucca (2005) shows that this formulation of the adjustment cost function is equivalent (up to first order) to a generalization of time to build.
} 
Fiscal policy is fully Ricardian: the Government finances its budget deficit by issuing short term bonds. Public spending is determined exogenously as a time-varying fraction of GDP

$$
G_{t}=\left(1-\frac{1}{g_{t}}\right) Y_{t}
$$

where $g_{t}$ is a disturbance following the stochastic process

$$
\log g_{t}=\left(1-\rho_{g}\right) \log g+\rho_{g} \log g_{t-1}+\varepsilon_{g, t}
$$

3.6. Market Clearing. The aggregate resource constraint is

$$
C_{t}+I_{t}+G_{t}+a\left(u_{t}\right) \bar{K}_{t-1}=Y_{t}
$$

3.7. Steady State and Model Solution. In this model, consumption, investment, capital, real wages and output evolve along a stochastic balanced growth path, since the technology process $A_{t}$ has a unit root. Therefore, we first rewrite the model in terms of detrended variables, compute the non-stochastic steady state of the transformed model, and then loglinearly approximate it around this steady state.

Finally, we estimate the approximated model using as observables the vector of variables

$$
\left[\Delta \log Y_{t}, \Delta \log C_{t}, \Delta \log I_{t}, \log L_{t}, \Delta \log \frac{W_{t}}{P_{t}}, \pi_{t}, R_{t}\right],
$$

where $\Delta \log X_{t} \equiv \log X_{t}-\log X_{t-1}$. A description of the data series used in the estimation can be found in appendix $\mathrm{A}$.

3.8. Bayesian inference and priors. We use Bayesian methods to characterize the posterior distribution of the structural parameters of the model (see An and Schorfheide (2005) for a survey). As in most of the literature, we assume that the model's exogenous disturbances are independent. This assumption is in contrast with that adopted by Chari, Kehoe, and McGrattan (2005), whose shocks are instead allowed to be correlated. Clearly, our assumption imposes additional restrictions on the model. On the other hand, independence is necessary for a meaningful structural interpretation of the shocks. 
The parameters' posterior distribution combines the likelihood and the prior information. In the rest of this subsection we briefly discuss the assumptions about the prior.

First, we fix a small number of parameters to values commonly used in the literature. In particular, we set the steady state share of capital income $(\alpha)$ to 0.33 , the quarterly depreciation rate of capital, $\delta$, to 0.025 and the steady state government spending to GDP ratio, $1-1 / g$, to 0.22 , which corresponds to the average value of $G_{t} / Y_{t}$ in our sample.

Table 1 reports the priors for the remaining parameters of the model. These priors are relatively disperse and are broadly in line with those adopted in previous studies (Altig, Christiano, Eichenbaum, and Linde (2005), Del Negro, Schorfheide, Smets, and Wouters (2004) or Levin, Onatski, Williams, and Williams (2005)). We discuss the posterior estimates of the parameters in the next section.

\section{Empirical RESUlts For the BASEline Model}

This section reports parameter estimates and the variance decomposition for the baseline model of section 3. Here and in what follows we use the fraction of the variance of the observables explained by each shock as a measure of the shock's contribution to fluctuations. Our objective is to establish the importance of intertemporal disturbances as sources of those fluctuations.

Table 2 presents posterior medians, standard deviations and 90 percent posterior intervals for the estimated coefficients of the baseline model. The estimates are reasonable and in line with values obtained by previous studies (Altig, Christiano, Eichenbaum, and Linde (2005), Del Negro, Schorfheide, Smets, and Wouters (2004), Levin, Onatski, Williams, and Williams (2005), Justiniano and Primiceri (2005)).

Table 3 reports the variance decomposition for the baseline model. Two points deserve particular attention.

First, the disturbance to the stochastic discount factor is the most important shock in explaining consumption fluctuations. The $b_{t}$ shock accounts 
alone for almost 50 percent of the variance of consumption growth. Its important role might be surprising, given that the baseline model features habit formation in consumption. In fact, habits should help explain the observed persistence in consumption, thus mitigating the empirical failure of the Euler equation. However, the introduction of habits is also associated with high variability of the risk-free rate, as observed for example by Boldrin, Christiano, and Fisher (2001) and Campbell and Cochrane (1999). This might contribute to explain the importance of $b_{t}$ in our framework.

The second important observation from Table 3 is that the investment specific technology shock $\mu_{t}$, another intertemporal disturbance, is by far the most important source of fluctuations in investment, as well as hours and output. This disturbance explains about 60 percent of the variability of investment growth, 57 percent of the variability of hours worked and 40 percent of the variability of output growth. Neutral technology shocks account only for one forth of the variance of GDP growth and 12 and 15 percent of the variance of hours and investment growth respectively. Finally, monetary policy shocks play a negligible role in generating fluctuations. They account for only 5 percent of the variance of GDP.

In summary, the empirical evidence from the baseline model clearly points to the crucial role of intertemporal disturbances in business cycle fluctuations, since they account for a very large portion of the variation in consumption, investment, output and hours. This finding is very consistent with the results in Greenwood, Hercowitz, and Krusell (2000), Fisher (2005) and Justiniano and Primiceri (2005) and broadly in line with some recent work that has dehemphasized the role of neutral technology as a source of business cycles (Gali (1999), Christiano, Eichenbaum, and Vigfusson (2004), Francis and Ramey (2005a and b)).

On the contrary, the importance of intertemporal disturbances, especially as sources of fluctuations in hour, is at odds with the results of Hall (1997), who attributes almost all those fluctuations to intratemporal preference shocks $\left(\varphi_{t}\right)$. However, in Hall (1997), as well as in Chari, Kehoe, and McGrattan (2005), who reach similar conclusions, the intratemporal wedge 
can be extracted directly, as a function of the model's observables (and some calibrated parameters.) In our framework instead two frictions break this link: habit formation and sticky wages. A closer inspection of their quantitative role reveals that habit formation is particularly important in this respect. In fact, when habit formation is restricted to zero, the intratemporal preference shock explains 77 percent of the variance of hours, a number much closer to Hall's (1997).

We undertake a more systematic assessment of the relative role of the various ingredients of the model in producing the results in the next section.

\section{Assessing the ROLE OF FRICtions}

What features of the baseline model are responsible for amplifying the role of intertemporal shocks as a source of fluctuations? In section 2 we argued that the main difference between an RBC model with wedges and our model is the fact that the latter includes a pricing equation for the nominal bond and observations on its interest rate. However, this is not the only difference between the two models. In fact, our baseline model includes a host of real and nominal frictions, like sticky wages, variable capital utilization, adjustment costs in investment and habit formation in consumption. All these frictions modify the model's representation of the relevant margins for intertemporal substitution. They could therefore play an important role in shifting the main source of fluctuations from intratemporal to intertemporal shocks. To asses the relative contribution of different frictions to this shift, this section compares the variance decomposition of the baseline model to that of a prototypical real model and of two intermediate specifications.

5.1. A prototypical growth model. The real model we consider is the stochastic growth core of the model of section 3. This is obtained by assuming perfectly flexible prices and wages, no habit in consumption, a fixed capital utilization rate and no adjustment costs in investment. The shocks we consider in this case are the neutral and investment specific technology shocks, $z_{t}$ and $\mu_{t}$, the intratemporal preference shock, $\varphi_{t}$ and the government spending shock, $g_{t}$. This is similar to the specification adopted by 
Chari, Kehoe, and McGrattan (2005), and we follow them in including only output, consumption, investment and hours worked as observable variables in the estimation. The variance decomposition for this model is in table 4 .

The results are in line with the macroeconomic conventional wisdom. The fluctuations in output and hours are entirely explained by the intratemporal shocks. The neutral technology shock explains 60 percent of output variability, with the remainder almost exclusively due to the intratemporal preference shock, which also accounts for 95 percent of fluctuations in labor, an even more extreme result than Hall's (1997). However, the intertemporal shock $\left(\mu_{t}\right)$ does play a role in generating fluctuations in investment, and especially in consumption, even in this simple economy. This suggests that, although the standard Euler Equation prices capital better than bonds (Mulligan (2002a)), its fit is far from perfect perfect. ${ }^{7}$

The impulse responses in figure 2 clarify the intuition behind this result. In the prototypical growth model, the fluctuations in consumption and investment generated by the intertemporal shock offset each other, leaving no role for this shock to explain output. This is because embodied technological progress generates a negative conditional correlation between consumption and investment, which leaves output almost unchanged. As a consequence, the likelihood would rather load on other shocks to generate business cycles, since consumption and investment are both procyclical.

5.2. The role of real frictions. Can real rigidities alone account for the paramount role of intertemporal disturbances in the baseline model? The answer is no, as clearly illustrated by the results in table 5 . Here, we augment the prototypical growth model described above with all the real frictions also featured in the baseline model. They are habit in consumption, variable capital utilization, investment adjustment costs and (real) wage rigidity.

The variance decomposition for this model is virtually identical to that of the previous model without frictions. Mechanically, the reason for the

\footnotetext{
7 In fact, Mulligan (2002a) shows that the standard consumption Euler equation correctly prices the after-tax return on capital. Our estimated intertemporal disturbance might therefore simply reflect the absence of taxes in our model.
} 
similarity of the results is that the posterior estimates of the parameters imply a small deviation from the frictionless model, with a limited degree of habit persistence and wage stickiness, and low investment adjustment costs. This is because the main role of rigidities is to generate a plausible transmission mechanism for the intertemporal shocks, as we will see in more detail below. But in a model with no bonds and only one Euler equation, such a mechanism is unnecessary, because intertemporal shocks can still be safely ignored when accounting for business cycles - the one Euler equation does not need too much help from exogenous disturbances to fit the data. We conclude that, from the vantage point of real models, intratemporal first order conditions are the ones in need of more urgent work, as also suggested by Chari, Kehoe, and McGrattan (2005).

\subsection{The role of interest rates and the bond Euler equation. The} next step is then to consider a model with nominal bonds and interest rates. We do so by adding price stickiness to the stochastic growth model, or equivalently by stripping the fully-fledged model of the consumption, investment and wage rigidities. Compared to the two real models described above, this specification has three more observables, price and wage inflation and nominal interest rates, and three more shocks, to monetary policy $\left(\varepsilon_{t}^{M P}\right)$, the price mark-up $\left(\lambda_{p, t}\right)$ and the discount factor $\left(b_{t}\right)$. Of these changes, the most important for our purposes is the inclusion of the nominal interest rate among the observables, and of the corresponding Euler equation among the optimization conditions. This is the equation often tested, and overwhelmingly rejected, in the finance literature.

The decomposition of the sources of fluctuations in this model is presented in table 6. Two results stand out. First, the sum of the two intertemporal shocks now explains 82 and 61 percent of consumption and investment fluctuations respectively, almost twice as much as in the simple growth model. Moreover, 78 and 34 percent of the fluctuations in the nominal interest rate and inflation are due to those same shocks. Our empirical procedure can satisfy the restrictions imposed by the two Euler equations, in a way which is compatible with the observed evolution of the nominal interest rate, 
consumption and investment, only by loading significantly on both the intratemporal shocks. This is a result of the Euler equation's failure as a restriction on the returns measured in financial markets.

The second important result emerging from table 6 is that the variability of output and labor remains an overwhelmingly intratemporal phenomenon. The effect of the intertemporal shocks is confined to fluctuations in consumption and investment, but these fluctuations still largely offset each other, resulting in virtually no movement in output and hours. This is because the model's transmission mechanism is not rich enough to propagate the intertemporal shocks from consumption and investment to hours and output. This propagation is achieved only with the inclusion of real frictions, as illustrated by the variance decomposition for the baseline model in table 3. Here, the intertemporal shocks together account for 41 percent of the fluctuations in output and 58 percent of those in labor, with the investment specific technology shock playing the key role.

Figure 3 illustrates the economic mechanisms underlying this result. As in all the models, an investment specific shock produces an investment boom. Without frictions, this is mostly financed by a reduction in consumption, with output almost unchanged. This is clearly not a business cycle (Greenwood, Hercowitz, and Krusell (2000) and Greenwood, Hercowitz, and Huffman (1988)). In the model with frictions, on the other hand, the investment boom is more gradual, due to the adjustment costs, and the reduction in consumption is kept in check by habits. At the same time, the sensitivity of the marginal utility of income to this change in consumption is high, amplifying the positive shift in labor supply. Moreover, the increase in demand triggered by the investment boom leads firms to hire more labor. And since wage stickiness flattens the labor supply curve, the result is a significant increase in hours. In addition, the drop in the relative price of new capital makes it optimal to increase the utilization rate, which further supports the increase in output. This increase in output in turn finances some of the investment boom, relieving the pressure on consumption, which in fact turns positive approximately two years after the shock. 
In sum, real and nominal frictions are complementary in attributing to intertemporal shocks a paramount role as sources of fluctuations. Including bond pricing among the criteria for judging a model's ability to fit the data is necessary to highlight the deficiencies of the standard theory of intertemporal substitution. These deficiencies manifest themselves as the shocks needed to explain investment and consumption fluctuations in the nominal model with no real rigidities. In this model, however, the intertemporal shocks are not viable sources of business cycle fluctuations, because they tend to move consumption and investment in opposite directions. The real frictions included in the baseline model reduce significantly the negative comovement between consumption and investment, contributing to the transmission of the intertemporal shocks to the rest of the economy.

Why should we believe the conclusions drawn from the baseline model rather than from the model without real frictions? The reason is that the baseline model fits the data much better. In fact, the log marginal data densities for the two specifications are equal to -2031.84 and -2224.53 respectively. These values imply huge posterior odds in favor of the baseline model.

5.4. A prototypical New-Keynesian model. The last experiment we conduct is with a prototypical New-Keynesian model. This is a model without capital accumulation dynamics. We derive it as a restricted version of the baseline model of section 3 with no investment, so that capital is constant over time.

Although it might not provide a particularly realistic description of the economy, this model is interesting because it is the polar opposite of the prototypical growth model of Chari, Kehoe, and McGrattan (2005) and section 5.1. In fact, the only intertemporal first order condition in our New-Keynesian model is the bond pricing equation, while the growth model only features the pricing equation for the capital stock. As expected, the analysis of this model produces opposite conclusions to those reached by Chari, Kehoe, and McGrattan (2005) and Hall (1997). 
To compare our results with those in the New-Keynesian literature, we estimate the model using only data on output, inflation and the short-term nominal interest rate. These observables only allow us to identify a subset of the shocks in the baseline model: the technology $\left(z_{t}\right)$, monetary policy $\left(\varepsilon_{t}^{M P}\right)$, mark-up $\left(\lambda_{p, t}\right)$ and discount factor $\left(b_{t}\right)$ shocks.

As expected, the analysis of this model produces opposite conclusions to those reached by Chari, Kehoe, and McGrattan (2005) and Hall (1997). First, the introduction of the discount factor shock $\left(b_{t}\right)$ improves the model's fit dramatically with respect to the case without that shock. The log marginal data density equals -872.64 for the model with variable $b_{t}$, while it decreases to -914.03 for the specification with a constant discount factor, implying very high posterior odds in favor of the baseline model.

Second, the shock to the stochastic discount factor explains 75 percent of the unconditional variance of GDP growth, as shown in table 7 , while the technology and monetary policy shocks only explain 23 and 2 percent of that variance. ${ }^{8}$

These results further corroborate our conclusion that intertemporal disturbances play a crucial role in models that explicitly include a bond-pricing equation among their constraints. This is the case, in particular, in models of the monetary transmission mechanism in which the short-term interest rate is the instrument of monetary policy.

\section{Concluding Remarks}

"If asset markets are screwed up, so is the equation of marginal rate of substitution and transformation in every macroeconomic model, so are those models' predictions for quantities, and so are their policy and welfare implications. Asset markets will have a greater impact on macroeconomics if their economic explanation fails than if it succeeds" (Cochrane (2005), p.3).

\footnotetext{
8 A similar result on the importance of the $b_{t}$ shock is obtained by Justiniano and Preston (2005) in an open economy framework.
} 
In this paper we followed Cochrane's (2005) advice, leveraging a wellknown failure of the standard consumption Euler equation to learn something new and surprising about the underlying sources of macroeconomic fluctuations. The conventional wisdom in macroeconomics, as expounded for example by Hall (1997) and Chari, Kehoe, and McGrattan (2005), is that fluctuations derive in large part from intratemporal disturbances. We showed instead that, in an estimated state-of-the-art model of the business cycle, intertemporal disturbances are responsible for more than 40 percent of output fluctuations, close to 70 percent of fluctuations in consumption and investment, and about 60 percent of fluctuations in hours worked.

The key to this surprising result is the inclusion of the pricing equation for bonds among the model's equilibrium conditions and of their return among the observables. As documented by a long line of research in finance, this Euler equation fits the data very poorly. In our general equilibrium framework, this statistical statement is equivalent to the presence of large intertemporal disturbances. We show that these disturbances are economically important, in the sense that they explain a large fraction of economic fluctuations. Models that ignore this basic pricing implication are likely to reach the opposite conclusion.

\section{Appendix A. The Data}

Our dataset spans a sample from 1954QIII to 2004QIV. All data are extracted from the Haver Analytics database (series mnemonics in parenthesis). Following Del Negro, Schorfheide, Smets, and Wouters (2004), we construct real GDP by diving the nominal series (GDP) by population (LF and LH) and the GDP Deflator (JGDP). Real series for consumption and investment are obtained in the same manner, although consumption corresponds only to personal consumption expenditures of non-durables $(\mathrm{CN})$ and services (CS), while investment is the sum of personal consumption expenditures of durables (CD) and gross private domestic investment (I). Real wages corresponds to nominal compensation per hour in the non-farm business sector (LXNFC), divided by the GDP deflator. We measure the 
labor input by the log of hours of all persons in the non-farm business sector (HNFBN), divided by population. The quarterly log difference in the GDP deflator is our measure of inflation, while for nominal interest rates we use the effective Federal Funds rate. We do not demean or detrend any series. 


\section{REFERENCES}

Altig, D., L. J. Christiano, M. Eichenbaum, And J. Linde (2005): "Firm-Specific Capital, Nominal Rigidities and the Business Cycle," NBER Working Paper No. 11034. An, S., ANd F. Schorfheide (2005): "Bayesian Analysis of DSGE Models," mimeo, University of Pennsylvania.

Boldrin, M., L. J. Christiano, and J. Fisher (2001): "Habit Persistence, Asset Returns and the Business Cycle," American Economic Review, 91, 149-166.

Calvo, G. (1983): "Staggered Prices in a Utility-Maximizing Framework," Journal of Monetary Economics, 12(3), 383-98.

Campbell, J. Y. (2003): "Consumption-Based Asset Pricing," in Handbook of the Economics of Finance, ed. by G. Constantinides, M. Harris, and R. Stulz, vol. 1B, chap. 13, pp. 803-887. North-Holland, Amsterdam.

Campbell, J. Y., And J. H. Cochrane (1999): "By Force of Habit: A Consumption Based Explanation of Aggragate Stock Market Behavior," Journal of Political Economy, 109, 1238-87.

Chari, V., P. J. Kehoe, and E. R. McGrattan (2005): "Business Cycle Accounting," Federal Reserve Bank of Minneapolis, Research Department Staff Report 328.

Christiano, L. J., M. Eichenbaum, And C. L. Evans (2005): "Nominal Rigidities and the Dynamic Effect of a Shock to Monetary Policy," The Journal of Political Economy, 113(1), 1-45.

Christiano, L. J., M. Eichenbaum, And R. Vigfusson (2004): "What Happens After a Technology Shock?," mimeo, Northwestern University.

Cochrane, J. H. (2005): "Financial Markets and the Real Economy," mimeo, University of Chicago.

Del Negro, M., F. Schorfheide, F. Smets, And R. Wouters (2004): "On the Fit and Forecasting Performance of New Keynesian Models," Federal Reserve Bank of Atlanta Working Paper No. 2004-37.

Eichenbaum, M., L. P. Hansen, And K. J. Singleton (1988): "A Time-Series Analysis of Representative Agent Models of Consumption and Leisure Choice under Uncertainty," Quarterly Journal of Economics, 103, 51-78.

Erceg, C. J., D. W. Henderson, And A. T. Levin (2000): "Optimal Monetary Policy with Staggered Wage and Price Contracts," Journal of Monetary Economics, 46(2), 281313.

Fisher, J. D. M. (2005): "The Dynamic Effect of Neutral and Investment-Specific Technology Shocks," mimeo, Federal Reserve Bank of Chicago. 
Francis, N. R., And V. A. Ramey (2005a): "Is the Technology-Driven Real Business Cycle Hypothesis Dead? Shocks and Aggregate Fluctuations Revisited," Journal of Monetary Economics, forthcoming.

_ (2005b): "Measures of Hours Per Capita and their Implications for the Technology-Hours Debate," University of California, San Diego, mimeo.

Gali, J. (1999): "Technology, Employment, and the Business Cycle: Do Technology Shocks Explain Aggregate Fluctuations?," American Economic Review, 89(1), 249-271.

Greenwood, J., Z. Hercowitz, And G. W. Huffman (1988): "Investment, Capacity Utilization, and the Real Business Cycle," American Economic Review, 78(3), 402-417.

Greenwood, J., Z. Hercowitz, and P. Krusell (1997): "Long Run Implications of Investment-Specific Technological Change," American Economic Review, 87(3), 342-362.

Greenwood, J., Z. Hercowitz, And P. Krusell (2000): "The role of investmentspecific technological change in the business cycle," European Economic Review, 44(1), $91-115$.

Hall, R. E. (1988): "Intertemporal Substitution in Consumption," Journal of Political Economy, 96(2), 339-357.

- (1997): "Macroeconomic Fluctuations and the Allocation of Time," Journal of Labor Economics, 15(2), 223-250.

Hansen, L. P., And K. J. Singleton (1982): "Generalized Instrumental Variables Estimation of Nonlinear Rational Expectations Models," Econometrica, 50, 1269-1286.

_ (1983): "Stochastic Consumption, Risk Aversion, and Temporal Behavior of Asset Returns," Journal of Political Economy, 91, 249-268.

Justiniano, A., And B. Preston (2005): "Can Structural Small Open Economy Models Account for the Influence of Foreign Shocks?," mimeo, Board of Governors of the Federal Reserve System, Washington D.C.

Justiniano, A., And G. E. Primiceri (2005): "The Time Varying Volatility of Macroeconomic Fluctuations," NBER Working Paper no. 12022.

King, R. G., And S. T. Rebelo (1999): "Resuscitating Real Business Cycles," in Handbook of Macroeconomics, ed. by J. B. Taylor, and M. Woodford, Amsterdam. NorthHolland.

Levin, A. T., A. Onatski, J. C. Williams, And N. Williams (2005): "Monetary Policy Under Uncertainty in Micro-Founded Macroeconometric Models," in NBER Macroeconomics Annual.

LuccA, D. O. (2005): "Resuscitating Time to Build," mimeo, Northwestern University. Mankiw, N. G., J. RotemberG, And L. Summers (1985): "Intertemporal Substitution in Macroeconomics," Quarterly Journal of Economics, 100, 225-251.

Mulligan, C. B. (2002a): “Capital, Interest, and Aggregate Intertemporal Substitution," NBER working paper no. 9373. 
(2002b): "A Century of Labor-Leisure Distorsion," NBER working paper no. 8774 .

(2002c): "A Dual Method of Empirically Evaluating Dynamic Competitive Equilibrium Models with Market Distorsions, Applied to the Great Depression and World War II," NBER working paper no. 8775.

- (2004): "Robust Aggregate Implications of Stochastic Discount Factor Volatility," NBER working paper no. 10210.

Prescott, E. C. (1986): "Theory Ahead of Business Cycle Measurement," Federal Reserve Bank of Minneapolis Quarterly Review, 10(4), 9-22.

Singleton, K. J. (1990): "Specification and Estimation of Intertemporal Asset Pricing Models," in Handbook of Monetary Economics, ed. by B. Friedman, and F. Hahn. NorthHolland, Amsterdam.

Smets, F., AND R. Wouters (2003a): "An Estimated Stochastic Dynamic General Equilibrium Model of the Euro Area," Journal of the European Economic Association, $1(5), 1123-1175$.

- (2003b): "Shocks and Frictions in US Business Cycles: A Bayesian Approach," mimeo, European Central Bank.

Woodford, M. (2003): Interest and Prices: Foundations of a Theory of Monetary Policy. Princeton University Press, Princeton, NJ. 
Northwestern University AND NBER

E-mail address: g-primiceri@northwestern.edu

Northwestern University

E-mail address: e-schaumburg@northwestern.edu

Federal Reserve Bank of New York

E-mail address: andrea.tambalotti@ny.frb.org 


\begin{tabular}{|c|c|c|c|}
\hline Coefficient & DENSITY & MEAN & STDEV \\
\hline$\iota_{p}$ & Beta & 0.5 & 0.15 \\
\hline$\iota_{w}$ & Beta & 0.5 & 0.15 \\
\hline$\gamma$ & Normal & 0.5 & 0.025 \\
\hline$h$ & Beta & 0.5 & 0.1 \\
\hline$\lambda_{p}$ & Normal & 0.15 & 0.05 \\
\hline$\lambda_{w}$ & Normal & 0.15 & 0.05 \\
\hline$\pi$ & Normal & 0.5 & 0.1 \\
\hline$r$ & Normal & 0.5 & 0.1 \\
\hline$\nu$ & Gamma & 2 & 0.75 \\
\hline$\xi_{p}$ & Beta & 0.75 & 0.1 \\
\hline$\xi_{w}$ & Beta & 0.75 & 0.1 \\
\hline$\chi$ & Gamma & 5 & 1 \\
\hline$S^{\prime \prime}$ & Normal & 4 & 1.5 \\
\hline$\phi_{\pi}$ & Normal & 1.7 & 0.3 \\
\hline$\phi_{y}$ & Gamma & 0.125 & 0.1 \\
\hline$\rho_{R}$ & Beta & 0.5 & 0.15 \\
\hline$\rho_{z}$ & Beta & 0.5 & 0.15 \\
\hline$\rho_{g}$ & Beta & 0.5 & 0.15 \\
\hline$\rho_{\mu}$ & Beta & 0.5 & 0.15 \\
\hline$\rho_{\lambda_{p}}$ & Beta & 0.5 & 0.15 \\
\hline$\rho_{\varphi}$ & Beta & 0.5 & 0.15 \\
\hline$\rho_{b}$ & Beta & 0.5 & 0.15 \\
\hline$\sigma_{R}$ & Inverse Gamma & 0.15 & 0.15 \\
\hline$\sigma_{z}$ & Inverse Gamma & 0.15 & 0.15 \\
\hline$\sigma_{g}$ & Inverse Gamma & 0.15 & 0.15 \\
\hline$\sigma_{\mu}$ & Inverse Gamma & 0.15 & 0.15 \\
\hline$\sigma_{\lambda_{p}}$ & Inverse Gamma & 0.15 & 0.15 \\
\hline$\sigma_{\varphi}$ & Inverse Gamma & 0.15 & 0.15 \\
\hline$\sigma_{b}$ & Inverse Gamma & 0.15 & 0.15 \\
\hline
\end{tabular}

TABLE 1. Prior densities for the model coefficients. 


\begin{tabular}{|c|c|c|c|c|}
\hline Coefficient & MEDIAN & StDeV & $5^{\text {th }}$ PERCENTILE & $95^{\text {th }}$ PERCENTILE \\
\hline$\iota_{p}$ & 0.165 & 0.067 & 0.081 & 0.296 \\
\hline$\iota_{w}$ & 0.099 & 0.029 & 0.056 & 0.151 \\
\hline$\gamma$ & 0.423 & 0.024 & 0.382 & 0.46 \\
\hline$h$ & 0.815 & 0.026 & 0.767 & 0.853 \\
\hline$\lambda_{p}$ & 0.241 & 0.038 & 0.178 & 0.304 \\
\hline$\lambda_{w}$ & 0.138 & 0.037 & 0.081 & 0.201 \\
\hline$\pi$ & 0.564 & 0.099 & 0.398 & 0.722 \\
\hline$r$ & 1.021 & 0.08 & 0.887 & 1.154 \\
\hline$\nu$ & 3.629 & 0.893 & 2.389 & 5.316 \\
\hline$\xi_{p}$ & 0.779 & 0.023 & 0.739 & 0.817 \\
\hline$\xi_{w}$ & 0.736 & 0.037 & 0.668 & 0.791 \\
\hline$\chi$ & 7.284 & 1.082 & 5.644 & 9.219 \\
\hline$S^{\prime \prime}$ & 1.728 & 0.491 & 1.142 & 2.725 \\
\hline$\phi_{\pi}$ & 2.043 & 0.142 & 1.842 & 2.305 \\
\hline$\phi_{y}$ & 0.068 & 0.014 & 0.046 & 0.091 \\
\hline$\rho_{R}$ & 0.8 & 0.022 & 0.76 & 0.833 \\
\hline$\rho_{z}$ & 0.321 & 0.055 & 0.233 & 0.413 \\
\hline$\rho_{g}$ & 0.977 & 0.007 & 0.964 & 0.988 \\
\hline$\rho_{\mu}$ & 0.924 & 0.024 & 0.877 & 0.956 \\
\hline$\rho_{\lambda_{p}}$ & 0.854 & 0.039 & 0.784 & 0.911 \\
\hline$\rho_{\varphi}$ & 0.494 & 0.07 & 0.372 & 0.607 \\
\hline$\rho_{b}$ & 0.832 & 0.039 & 0.766 & 0.894 \\
\hline$\sigma_{R}$ & 0.257 & 0.015 & 0.236 & 0.284 \\
\hline$\sigma_{z}$ & 1.168 & 0.066 & 1.071 & 1.287 \\
\hline$\sigma_{g}$ & 0.643 & 0.04 & 0.581 & 0.71 \\
\hline$\sigma_{\mu}$ & 0.127 & 0.018 & 0.103 & 0.159 \\
\hline$\sigma_{\lambda_{p}}$ & 0.103 & 0.011 & 0.086 & 0.123 \\
\hline$\sigma_{\varphi}$ & 1.077 & 0.261 & 0.718 & 1.608 \\
\hline$\sigma_{b}$ & 0.569 & 0.139 & 0.399 & 0.856 \\
\hline
\end{tabular}

TABLE 2. Posterior estimates for the coefficients of the baseline model. 
INTERTEMPORAL DISTURBANCES

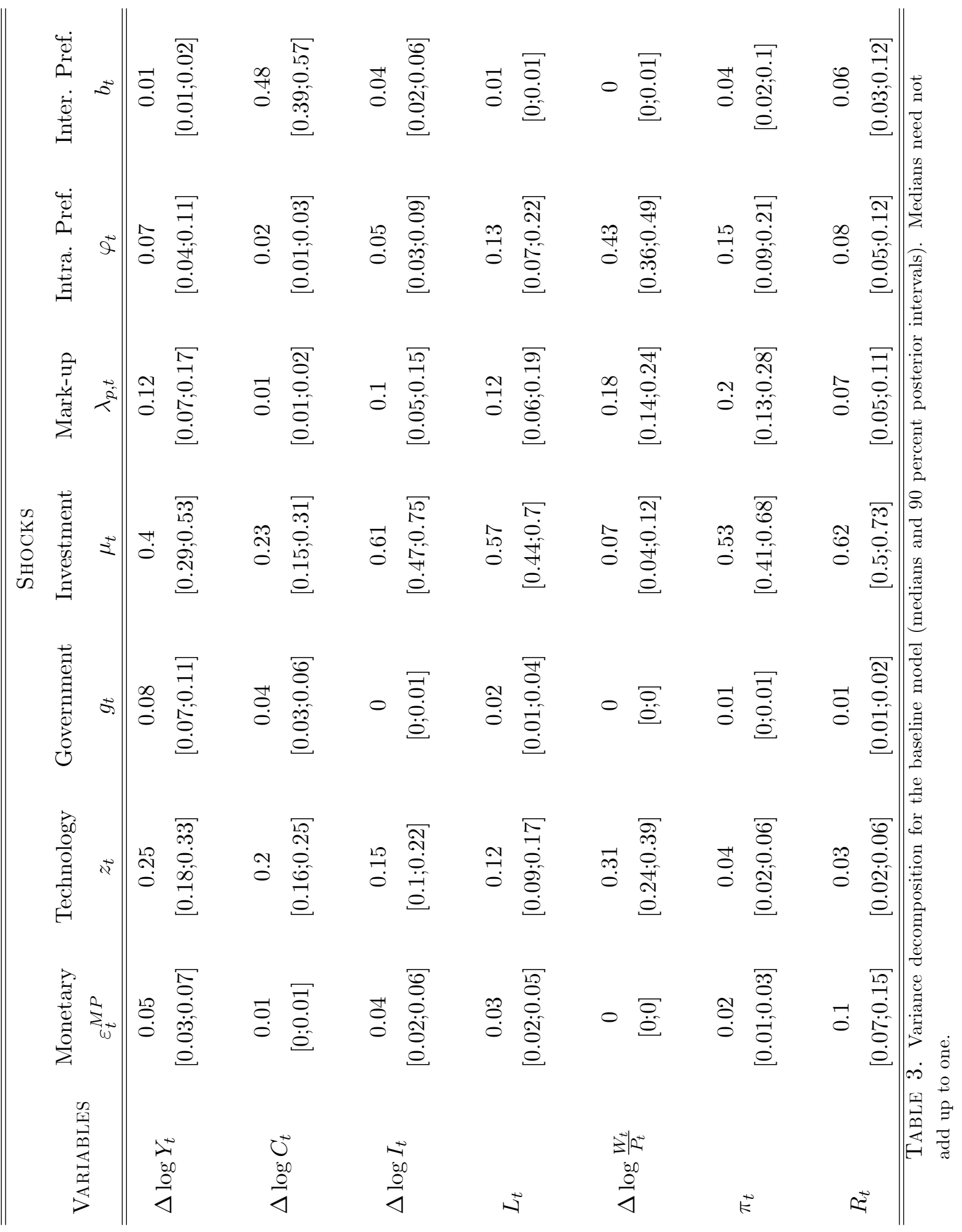




\begin{tabular}{ccccc}
\hline \hline \multirow{4}{*}{ VARIABLES } & Technology & Government & Investment & Intra. Pref. \\
& $z_{t}$ & $g_{t}$ & $\mu_{t}$ & $\varphi_{t}$ \\
\hline \hline \multirow{2}{*}{$\Delta \log Y_{t}$} & 0.60 & 0.01 & 0.02 & 0.37 \\
& {$[0.55 ; 0.65]$} & {$[0 ; 0.01]$} & {$[0.01 ; 0.03]$} & {$[0.32 ; 0.43]$} \\
& & & & \\
$\Delta \log C_{t}$ & 0.26 & 0.12 & 0.57 & 0.04 \\
& {$[0.22 ; 0.31]$} & {$[0.1 ; 0.16]$} & {$[0.52 ; 0.62]$} & {$[0.03 ; 0.06]$} \\
& & & & 0.25 \\
$\Delta \log I_{t}$ & 0.23 & 0.24 & 0.27 & {$[0.21 ; 0.3]$} \\
& {$[0.2 ; 0.27]$} & {$[0.18 ; 0.3]$} & {$[0.23 ; 0.33]$} & \\
& & & & 0.95 \\
$L_{t}$ & 0.01 & 0.01 & 0.04 & {$[0.91 ; 0.97]$} \\
\hline \hline
\end{tabular}

TABLE 4. Variance decomposition for the prototypical growth model (medians and 90 percent posterior intervals). Medians need not add up to one. 


\begin{tabular}{ccccc}
\hline \hline \multirow{4}{*}{ VARIABLES } & Technology & Government & Investment & Intra. Pref. \\
& $z_{t}$ & $g_{t}$ & $\mu_{t}$ & $\varphi_{t}$ \\
\hline \hline$\Delta \log Y_{t}$ & 0.61 & 0.00 & 0.04 & 0.35 \\
& {$[0.56 ; 0.67]$} & {$[0.00 ; 0.01]$} & {$[0.02 ; 0.06]$} & {$[0.3 ; 0.4]$} \\
& & & & \\
$\Delta \log C_{t}$ & 0.15 & 0.06 & 0.75 & 0.03 \\
& {$[0.12 ; 0.19]$} & {$[0.05 ; 0.09]$} & {$[0.7 ; 0.79]$} & {$[0.02 ; 0.06]$} \\
& & & & 0.21 \\
$\Delta \log I_{t}$ & 0.32 & 0.22 & 0.26 & {$[0.18 ; 0.24]$} \\
& {$[0.27 ; 0.37]$} & {$[0.17 ; 0.27]$} & {$[0.21 ; 0.31]$} & \\
& & & & 0.95 \\
$L_{t}$ & 0.01 & 0.01 & 0.03 & {$[0.91 ; 0.98]$} \\
\hline \hline
\end{tabular}

TABLE 5. Variance decomposition for the growth model with real frictions (medians and 90 percent posterior intervals). Medians need not add up to one. 
INTERTEMPORAL DISTURBANCES

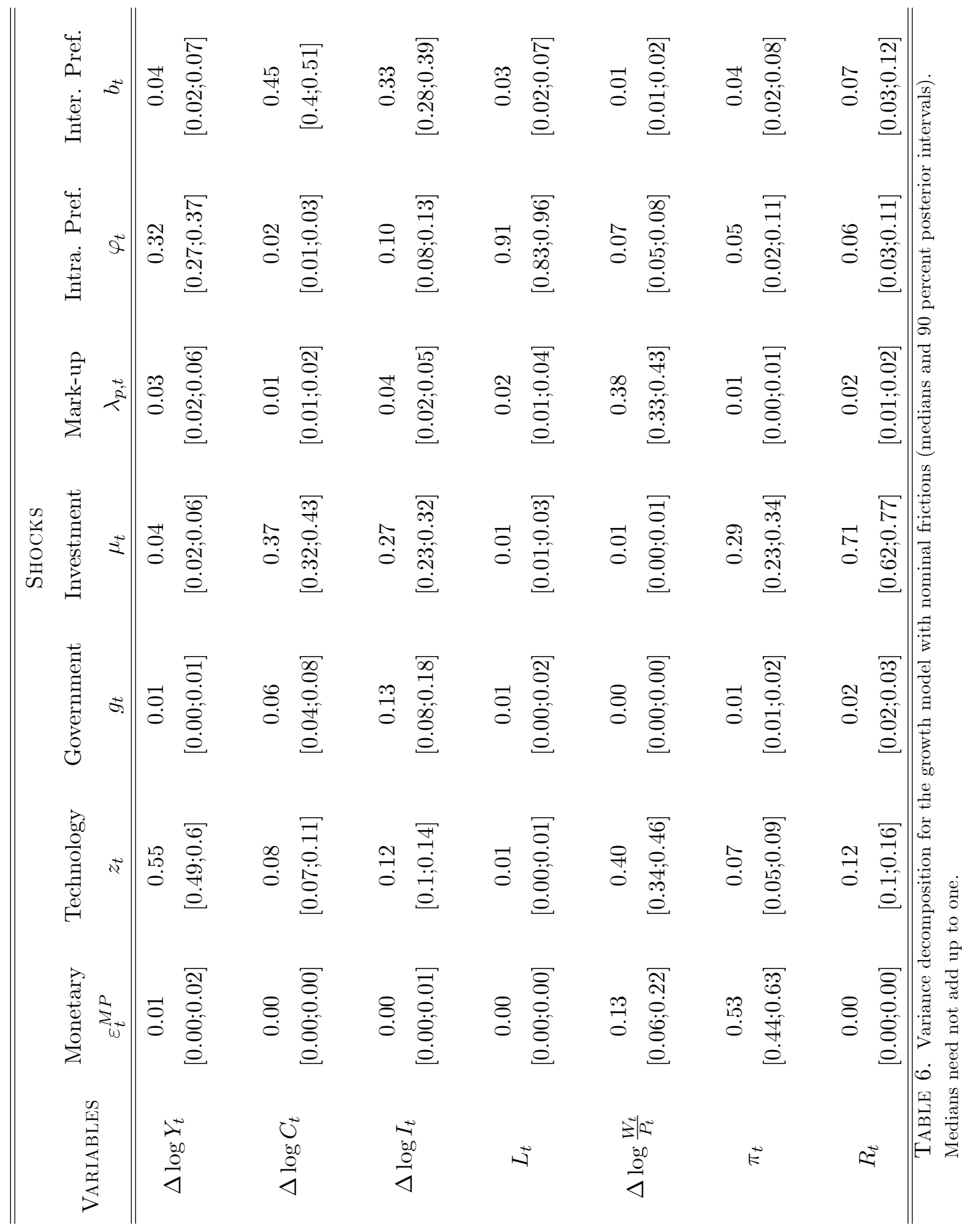




\begin{tabular}{ccccc}
\hline \hline & \multicolumn{4}{c}{ SHOCKS } \\
VARIABLES & Monetary & Technology & Mark-up & Inter. Pref. \\
& $\varepsilon_{t}^{M P}$ & $z_{t}$ & $\lambda_{p, t}$ & $b_{t}$ \\
\hline \hline \multirow{2}{*}{$\Delta \log Y_{t}$} & 0.02 & 0.23 & 0.01 & 0.75 \\
& {$[0.01 ; 0.03]$} & {$[0.14 ; 0.38]$} & {$[0 ; 0.02]$} & {$[0.59 ; 0.84]$} \\
& & & & \\
$\pi_{t}$ & 0 & 0 & 1 & 0 \\
& {$[0 ; 0]$} & {$[0 ; 0]$} & {$[0.99 ; 1]$} & {$[0 ; 0.01]$} \\
& & & & 0.47 \\
$R_{t}$ & 0.12 & 0 & 0.4 & {$[0.32 ; 0.61]$} \\
\hline \hline
\end{tabular}

TABLE 7. Variance decomposition for the prototypical NewKeynesian model (medians and 90 percent posterior intervals). Medians need not add up to one. 


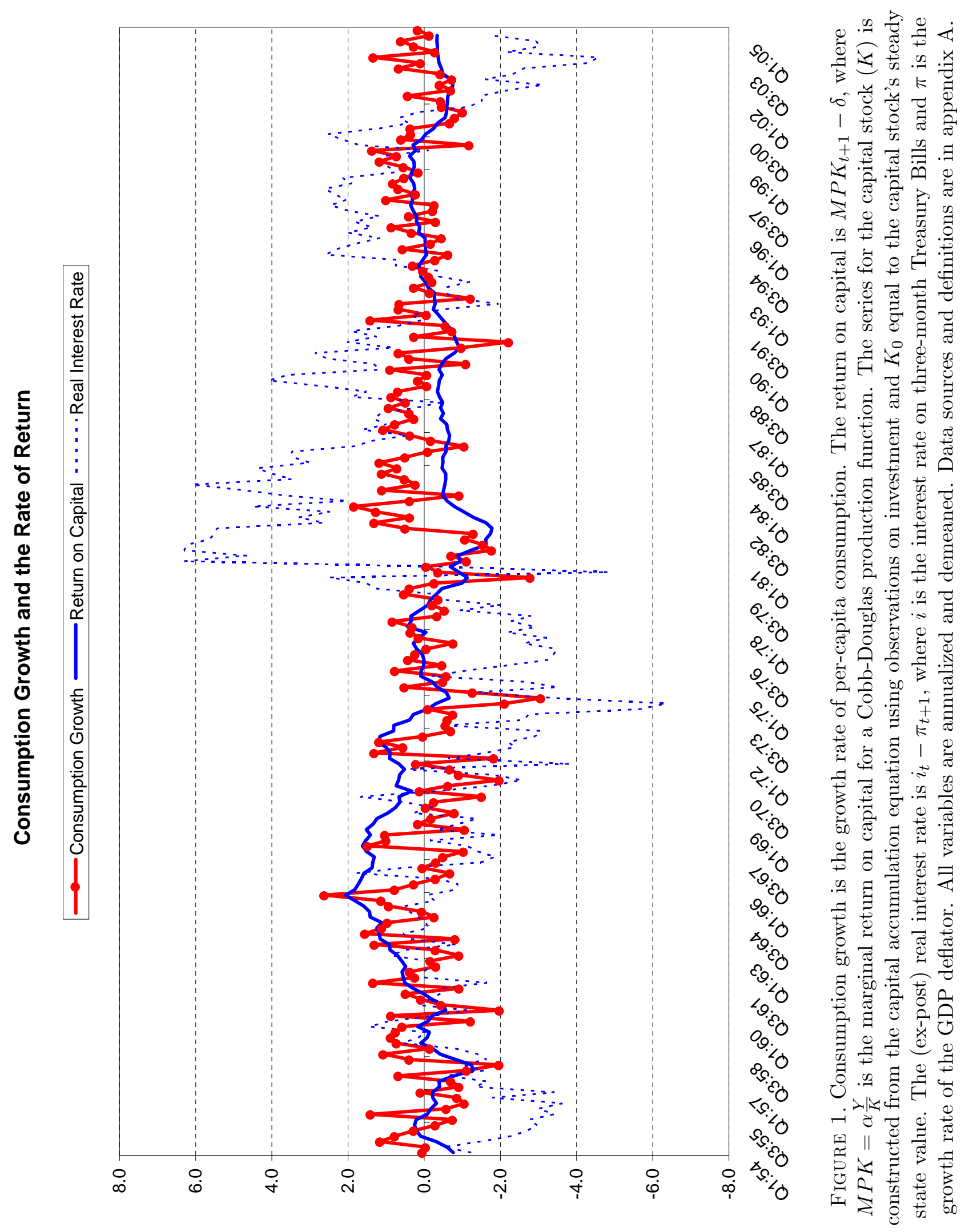



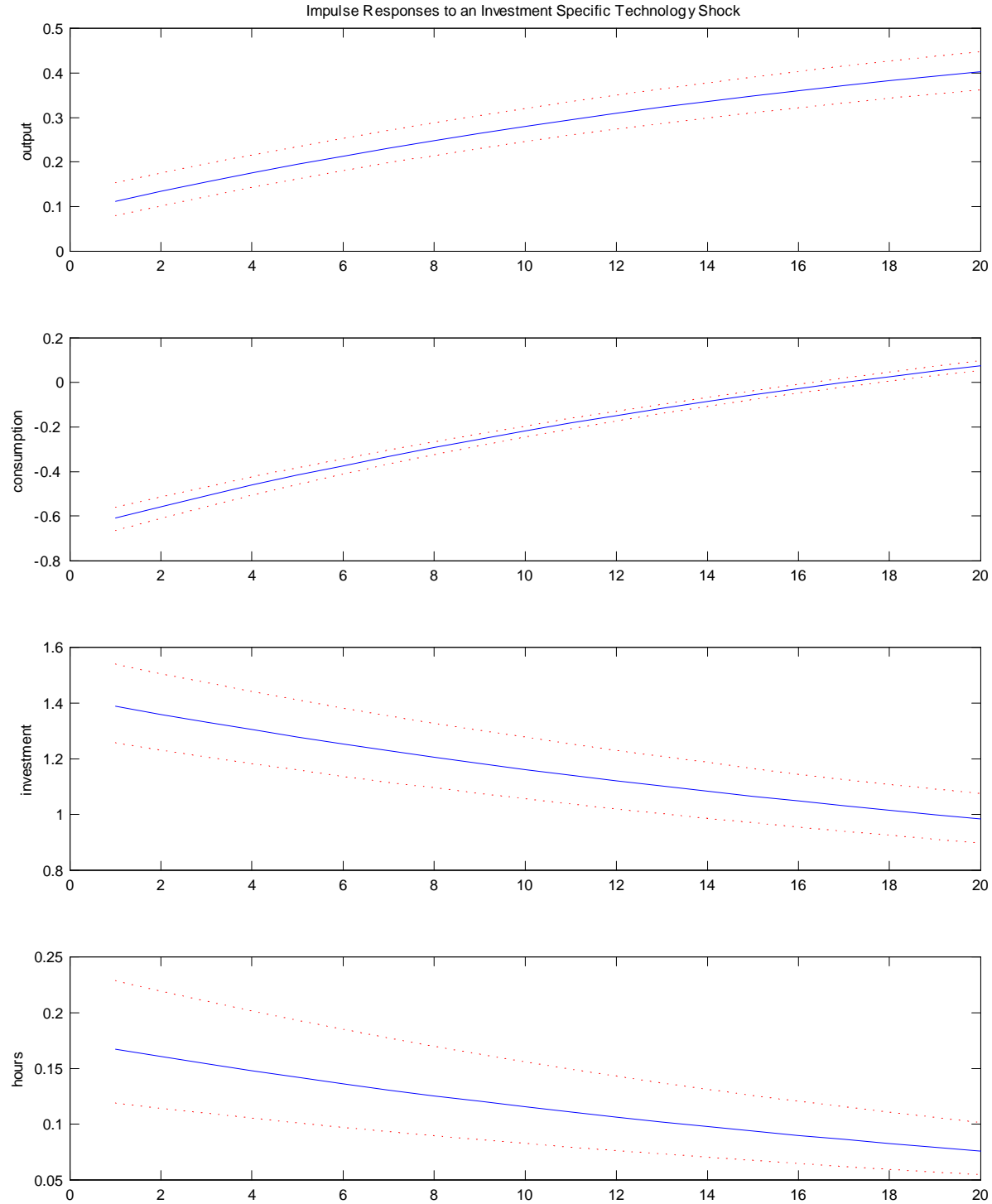

FIGURE 2. Impulse responses to an investment specific technology shock $\left(\mu_{t}\right)$ for the prototypical growth model (medians and 90 percent posterior intervals.) 

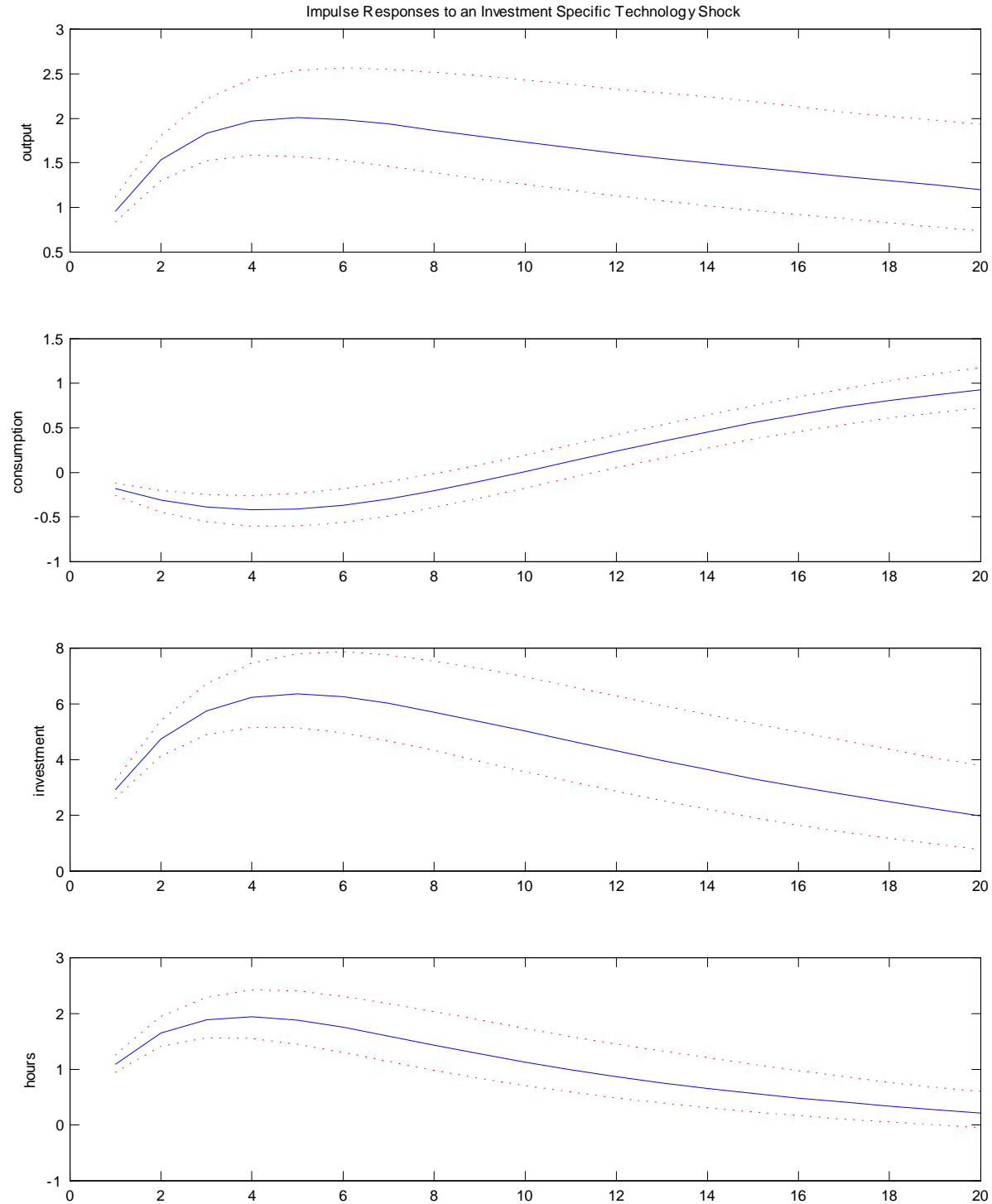

FIGURE 3. Impulse responses to an investment specific technology shock $\left(\mu_{t}\right)$ for the baseline model (medians and 90 percent posterior intervals.) 